\title{
Problem based learning (PBL): A conundrum
}

\section{Samantha H Wells}

School of Nursing, Deakin University, Waterfront Campus, Geelong, Victoria, Australia

\section{PhiLIP J Warelow}

School of Nursing, University of Ballarat, Ballarat, Victoria, Australia

\section{KaREN L Jackson}

School of Nursing, Deakin University, Waterfront Campus, Geelong, Victoria, Australia

\section{ABSTRACT}

Problem Based Learning (PBL) using minimal guided instruction is used as an educational strategy across a broad variety of disciplines in the tertiary sector. This paper includes some of the strengths and weaknesses of PBL, both in general and in relation to the health care setting, encompassing some of its philosophical underpinnings and its methodological approach. In an effort to explore some of the benefits and problems with PBL in the work setting, this account will comprise a realistic rather than idealistic focus and will include a range of perspectives from both a facilitator and student standpoint. We suggest that PBL is a useful strategy across a comprehensive nursing degree programme (as the ideal) provided the learning programme is supported financially and that its ideal creed which supports a small group approach are adhered to. What we find is that reality is often different, with individual facilitators condensing their PBL programmes to incorporate a modified PBL approach with this personalised approach often taking strength away from the original conceptions of PBL. What we suggest here is that these circumstances constitute a conundrum.

KEYwORDs: problem based learning; nursing; implementation; benefits; difficulties

\section{DEFINING PROBLEM BASED LEARNING}

Problem based learning is often referred to 2001). PBL originated at the McMaster School of Medicine in Canada in 1965 (Berkson, 1993), and was further refined by Dr. Howard Barrows as both a curriculum strategy and a process approach in 1988. As a curriculum, PBL consists of carefully designed and scripted problems/scenarios that demand a number/range of skills from the learner. These skills include: self-directed learning, critical thinking, team participation and acquisition of critical knowledge (Levine, 2001) and as argued by Capon and Kuhn (2004, p. 74) the blending of acquisition, recall and an integration of newly acquired concepts with existing knowledge structures. This amalgamation promotes the possibility of restructuring and enhancing the student's conceptual coherence or helps to make more sense of an issue. The PBL process involves a systematic approach to resolving problems or meeting challenges that are encountered in real-life situations including a person's career (Levine, 2001). Student independence, self direction and the autonomy given to the students have been considered the hallmarks of PBL (Rideout et al., 2002) such that 
the problem in many ways shapes and directs the learning (Finucane, Johnson, \& Prideaux, 1998) and is facilitated by using a range of simulation supports and also some of the unique e-learning accoutrements offered by some universities. Another cornerstone of PBL is lower studentlecturer ratios which students have reported allow for helpful and flexible learning and close studentlecturer relationships that are developed and fostered because of the small group format (Rideout et al., 2002, p. 12).

Recent work by Kirschner, Sweller, and Clark (2006) has argued that in problem based learning as well as other teaching strategies such as discovery and experiential learning, the premise of minimal guidance does not work. They clarify by saying that 'minimal guidance during instruction is significantly less effective and efficient than guidance specifically designed to support the cognitive processing necessary for learning (p. 76)'. Skilled problem solvers use long term memory to select and apply processes to achieve a solution, this application can cause issues with learning (Johnstone \& Otis, 2006). For many students they do not have the bank of long term memory to utilize in these circumstances, producing a novice-expert distinction. Work has already been carried out in this area by Benner (2000) but in relation to using PBL as a teaching strategy this has further ramifications for increased support of the students whilst undertaking PBL activities.

PBL as a strategy can also be seen to relate directly to the way nurses practice. In professional activities it is common that one deals with minimal information and attempts to solve problems and treat patients appropriately. However because of the past experiences of the practitioner they are able to swiftly select possible approaches to care and identify potential solutions. It could be argued that by using PBL in the curriculum we are equipping students to deal with problem solving on a practical level, given their minimal exposure to practice and guidance. The ethos is 'learning on the job' be it student or practitioner.
PBL as a teaching style is used by a number of tertiary sites across different faculties which suggest an acknowledgement of the merit of this particular approach. While Wilkie (2000) notes that PBL should ideally occur in small groups of say eight to ten people, reality is often significantly different. The variance of group numbers across specific teaching sites and the increase in some schools of enrolled students is quite significant. Often the central tenets of problem based learning are lost by trying to run problem based learning programmes with tutorial sizes of thirty five plus students. These figures vary but clearly those schools that have sizeable budgets (such as medicine) are more clearly able to have PBL groups of less than ten students. In contrast, schools with lesser budgets have PBL classes running with up to thirty five enrolled students and this issue is perhaps indicative of a whole range of political agendas and fiscal policy decisions which benefit some schools at the expense of others. On a day to day basis teaching this many students is likely to affect the PBL process and vary the way in which classes will run and because of this affect the educational outcomes and preparedness of students for practice. It is clear that each tutorial will take the PBL scenario/problem in different directions and diagnostic reasoning and a hypothesis about diagnosis will often vary on a range of similar themes. The advantage of this is that the students have freedom to examine areas as relevant to their own interests and learning needs, but conversely the nursing curricular demands a base level of knowledge and this approach does not necessarily guarantee this knowledge will be achieved and tends to teach down to the mediocre in an attempt to encapture all from a variety of different experiential levels, hence, the conundrum.

\section{BENEFITS OF PROBLEM BASED LEARNING}

As has already been stated problem based learning is a beneficial learning style for those joining the health professions, as they need to acquire a problem solving ability to deal with a variety of unique life and health situations (Norman, 2008). Whilst within the practice setting it is envisaged 
that students will develop the resources to work through a problem, by giving it a depth of consideration rather than just looking at it from just the surface. With this approach the PBL approach encourages its students to consider the issue on its individual merits and look to solve the issues by reflecting on and drawing together a considered experiential and theoretical knowledge base and bundle together data in a positive way forward rather than be concerned about what they do not know, for example in relation to a particular disease process, the students will be confident in their ability to work through a problem gaining appropriate knowledge as they do. This ability to work through a problem is therefore thought to outweigh the traditional methods of teaching where students are expected to passively absorb knowledge (Weyers, 2006). This more traditional style views students as 'passive receivers' or 'empty vessels.' Problem based learning requests of students an inquiring and/or critical mind which seeks to build onto a range of life skills and seek information by clustering segments of knowledge which moves students towards a hypothesis about the problem being investigated. Minimal guidance is offered across this approach and clearly some students find it quite appealing but Kirschner et al. (2006) advises caution suggesting that empirical studies over the past half century indicate that minimally guided methods are less effective and less efficient than instructional approaches that place a strong emphasis on guidance of the student learning process. Albanese and Mitchell (1993) in their comparison of PBL with conventional medical school instruction found a number of issues with PBL citing a range of negative factors such as impact, lower basic science exam scores, a requirement to study more and little difference between residency selections. Overall this study showed that PBL students received better scores for clinical performance but showed a preponderance to order many more tests (striving for certainty) which often skewed upwards the cost and allocated workload for each patient the fiscal implications of this add to the conundrum.
In a broader sense, which encompasses a multitude of positive career options, PBL is also thought to increase motivation, as students feel empowered to have an impact on the outcome of the case study and are invested in the solution to the problem being embarked upon (Marks, 2001). Schmidt (1983) and Marks (2001) argue that there are also increased opportunities for students to elaborate on their own knowledge base through more active involvement and verbalization within a team setting. Furthermore, PBL also encourages and shows the learner how to learn. This involves developing strategies for sourcing definitions, gathering rigorous academic information, data-analysis and hypothesis building (Marks, 2001) and articulating the salience of their views within a multidisciplinary framework in a professional and confident manner substantiating their health care using an evidence based approach.

The Federal Government of Australia highlighted concerns about traditional teaching methods in tertiary education in 1990 . They noted that Australian graduates, all too frequently are not 'analytical, creative thinkers... who are not sufficiently attuned to life-long learning' (p. 197). After such comments, PBL was implemented into many curriculums in an effort to encourage these skills at a tertiary level of education. From a nursing perspective analytical and creative thought has been encouraged by innovative programmes in some tertiary schools. For instance in some mental health units across nursing undergraduate comprehensive degree programs, actor simulation sessions are used (Edward, Hercelinskyj, Warelow, \& Munro, 2007). This links to the points raised above where students are able to see a range of symptomatology, treatment strategies/styles in relation to a mental illness allowing students to build on their limited knowledge base, recognize cues and triggers. Because of these simulated experiences and theoretical understandings, once in the clinical sites the students can more realistically implement their learning in the realities of practice environments.

A range of studies show that PBL students generally do as well as more traditionally educated 
counterparts under exam situations, and are seen as better practitioners (Levine, 2001). Studies by the San Diego State University (1996) found that students enrolled in problem based learning courses had a more favourable attitude towards their course than students educated in a more traditional manner. Problem based learning courses have also been reported as having an increase in course enrolment and more positive feedback from faculty and employers (Pincus, 1995); reduced student drop out rates (Bridges \& Hallinger, 1996); and a range of comments from students concerning the advantages of PBL after their learning experience (Bernstein, Tipping, Bercovitz, \& Skinner, 1995). Mentzelou (2004) also articulates that 'problem based curricula do appear to provide a friendlier and more inviting educational climate'. More recently, Rideout et al. (2002) carried out a comparison study between a conventional teaching program and a PBL course. There were statistically significant differences between the two groups, with $\mathrm{PBL}$ receiving higher ratings in regard to the role of the facilitators, program outcomes, student assessment, level of independence and overall satisfaction rates (Rideout et al., 2002).

\section{PBL DIFFICULTIES AND RECOMMENDED SOLUTIONS}

In teaching problem based learning one quickly realizes that $\mathrm{PBL}$ is not a pedagogy that suits everyone both from a student and lecturer perspective. In general terms the literature suggests that students from a variety of disciplines view PBL more positively than traditional curricula although there is a constant tension running through the literature which suggests that a small proportion of students do not appear to thrive in a PBL environment (Rowan, McCourt, \& Beake, 2008, p. 94). These tensions centred on uncertainty and anxiety relational to lack of course structure, stress in regard to finding resources and disquiet about the contributions or lack of input by other group members (Rowan et al., 2008). One of the most challenging areas of PBL is to make sure that each member of the team format participates in the learning process including the staff facilitator (Rowan, McCourt, Bick, \& Beake, 2007). While a facilitator may be aware that students will participate within the group to different degrees, there are certain problems for which the lecturer must watch. Specifically, this includes difficulties with particular group members as they are either overly assertive, by attempting to run the group and enforce their particular thoughts on the outcome of the problem or there are those students whose contribution to the group is minimal, consequently having a negative impact on the group yet still claiming participation and being involved in any rewards or grading attached. For example, where the group workload is not being shared evenly or assessments are not being completed adequately. The size of the group is also a factor of concern and highlights the aforementioned points whereby 'resentments' could occur (Rowan et al., 2008) if students did not follow the ground rules imposed by the larger cohort. Aside from these resentments it was clear that the PBL intent of the group was often subjugated because of fear of upsetting and challenging the views of others (Das Carlo, Swadi, \& Mpofu, 2003) where challenge and some of the more central tenets of PBL were seen as 'pointless because it was not truthful' (Rowan et al., 2007, p. 98). Additionally, Azer (2001) notes that student associated problems in the group include: a range of negative attitudes towards each other, poor communication skills, lack of support for one another, distraction or stress in the group, unresolved personal conflict and disregard for getting tasks completed on time. Similarly, the quieter students can often be overrun with the more forcefully articulated views of the stronger elements of the group negating the egalitarian ideal of the PBL approach (Steinert, 2004). The other noteworthy issue which is conveyed in the literature is being prepared to begin practice or to hit the ground running with many students anecdotally suggesting that they didn't feel prepared to embark on the practice component of their position. That however theoretically prepared they were, the application of this 
theoretical knowledge was always anxiety provoking, despite the PBL underpinning and in spite of the support provided (McCourt \& Thomas, 2001) which once again adds to the PBL puzzle.

One of the major challenges in PBL is a dysfunctional group (Azer, 2001). There are three features listed by a number of authors, including Azer that make for sound group dynamics. These include the participation of all group members (Crosby, 1996); the group has a well defined task with clear objectives (Azer, 2001); and the group learns and reflects on their experiences and modify their behaviour accordingly (Boud, Keogh, \& Walker, 1995). Furthermore, it has been noted that to implement these features into the group, one not only relies on a skilled facilitator and collaborative group, but also a well designed problem and it's relevance to the learning topic (Niederhoffer, 2000). Haith-Cooper (2002) notes that facilitators can strengthen group dynamics by asking permission before intervening so the group feels a sense of ownership over the outcome. Furthermore, a healthy learning environment where students are given positive feedback helps build trust between the facilitator and student, along with improving many students motivation and therefore their learning outcomes (Haith-Cooper, 2002).

\section{FACILITATION PROBLEMS}

The literature argues strongly that the success or otherwise of PBL has much to do with the role of the facilitator and the facilitator's role across the full programme (Hwang \& Kim, 2006; Rowan et al., 2007). The constant argument suggests that those facilitators who undervalue the benefits of the PBL style of teaching and are unwilling to implement it often say that the didactic is better. There are many facilitators that were not educated in the style of PBL and do not understand its educational philosophy and therefore become reluctant to participate. As a result of preferring the more traditional methods of teaching such as 'chalk and talk', or by using a combination/hybrid of the two has meant that PBL has evolved from its original conception advocated by the McMaster school in 1965. It seems clear that PBL asks its proponents to work across rather than within a set of parameters and that its implementation has and should work from an egalitarian base which is nicely described by Lloyd-Jones, Margetson, and Bligh (1998) as a 'coat of many colours'. Azer (2001) notes that often teachers tend to dominate tutorial groups and suppress the involvement of student communication, which is at the very core of problem based learning. There may also be issues with teachers being inexperienced regarding the PBL approach (Azer, 2001) and because of this reverting back to the more traditional teaching styles which more readily fall within their comfort zones. Knowles' (1975) work some three decades ago highlighted some of the difficulties that self-directed, problem based learning brings about for those people who have previously seen themselves as 'teachers' and now have to move into the role of 'facilitator'. Further, he stated that problem based learning was more student focused rather than focused on what the teacher was doing, arguing that it required that the teacher divest themselves of the 'protective shield of authority and expose [themselves as] an authentic human being. This will prove a real challenge for some as it requires [them] to extricate from the compulsion to pose as an expert who had mastered any given body of content'... and instead join the students as a co-learner (Knowles, 1975, p. 3). The co-learning alternative is the position promulgated by much of the literature and encompasses the bridge between theory and practice (McLoughlin \& Darvill, 2007; Williams, 2004).

Another challenge within PBL is if the problem/ scenario is not well designed (Azer, 2001) and not properly funded. Some of the simulation and e-learning components of many scenarios quickly become outdated and constant review of materials is required. Some schools use actors to emulate real life situations which promote indepth thinking on the part of the student, these are usually referred to as laboratories and are an excellent facilitative catalyst for students to practice some of the craft in relation to communicating with patients and some of the repertoire 
of skills required to practice nursing well. Other schools abandon excellent strategies because cost becomes the imperative rather than quality nursing care being delivered through these innovative programmes. Other problems include scenarios which contain inadequate information within the problem for the student to work with, lack of clear triggers allowing the student to develop rationales and develop, discrepancies between facilitator and students objectives, a lack of relevance to the student's clinical practice, material being outdated, and problems that are unrealistic (Hitchcock \& Anderson, 1997). This includes scenarios which are paper driven and task tidy and do not contain any emotional components which seem at odds with real life experiences and tends to promulgate the importance of theory over the practice. Marks (2001), supports this view in saying that the best designed PBL problems are in fact ill-structured and because of this simulate real-life experiences. He defines 'ill-structured problems' as being messy and complex in nature; they require inquiry, information gathering, and reflection; these problems are changing and tentative and lastly they have no simple, fixed, formulaic, right solution. By providing students with such complex issues, students are thought to be able to integrate this process of learning and work them into real-life situations and problem solve when faced with an issue. Therefore, PBL involves the students working through the process rather than relying on material they have rote learnt and which may not provide the answers (Southern Illinois University School of Medicine, 2000). With this in mind we argue here that a rethink of the promise of PBL is required. Norman and Schmidt (2000) agree with Colliver (2000) who suggests that a minimal difference results in both cognitive and clinical outcomes using a PBL approach and that some of the benefits also have a negative dimension. Additionally, students have indicated that their concerns within the classroom setting relate to a lack of clarity and direction regarding assignments, concerns about inconsistencies between facilitators and 'the repetitive, often positively-skewed peer evaluations that are part of a small group format' (Rideout et al., 2002, p. 7). Biley (1999, p. 586) also highlights 'tensions' which include making the transition to PBL from the more didactic approaches of primary and secondary education. Biley argues that feelings of insecurity can develop and these may be accompanied by uncertainty, anxiety, (Duke, Forbes, Hunter, \& Prosser, 1998, p. 60) and confusion which can lead to reduced learning efficiency. The second part of Biley's argument refers to students having difficulty remembering the aims across the PBL process and that the volume of knowledge (needing to be learnt) was often seen to be overwhelming and was mostly unknown with PBL not having the boundaries usually placed around a topic by more didactic, teacher/ expert driven pedagogical approaches. Candy (1994 cited in Williams, 1999) argues this point in a similar fashion suggesting that students often lacked confidence in performing technical skills, and were unable to differentiate what was normal or important and likened this to 'stumbling in the dark'. Williams furthers this point suggesting that motivated or mature students often tended to do better whereas the younger, often a didactically taught school leaver, was more likely to be overwhelmed and less confident which is indicative of the overall PBL conundrum.

Despite an array of positives often promulgated by authors about PBL as mentioned earlier many of these publications refer to problems with aspects of this academic approach. The challenge of PBL according to Williams (1999) is encompassed in the budgetary concerns whereby maintaining the quality of scenarios and keeping them up to date is suggested as problematical, similarly, Williams cites anecdotal evidence from students undertaking PBL coursework which indicates their dissatisfaction with the less formal structures of PBL and requests for more formal teaching to compensate for students who believed that they taught themselves. This dissatisfaction forms part of the puzzle in that students expect more improved resources and value for their educational fees and self directed learning tends to 
not marry well with these beliefs. Clinical preparedness was another feature common across the literature (Banning, 2005; Kenny \& Beagan, 2004; Williams, 1999) with an overriding view that students learn more a detached concern for patients with an almost emotional detachment such that nurses treat the illness (the condition) rather than the person with the condition and in the absence of facilitator input nurses can almost depersonalize the patient. The person with an illness becomes the diabetic, fractured NOF, the schizophrenic which by extension sounds entirely at odds or a conundrum with the professional stance in nursing which extols caring as its foundational benchmark.

\section{FACILITATOR SUPPORT}

Despite PBL often being self-directed by students, Maudsley (1999), notes that it is still the responsibility of the facilitator to support the student. That is, the facilitator's role can be undermined by wrongly viewing 'student-centered' as 'tutor inactive'. The facilitator must be aware that they still need to impart their wisdom, but only when required. That is, thought provoking comments by the facilitator or playing almost a 'devil's advocate role' which intellectually challenges and stimulates the student which encourages and guides the breadth and depth of their learning without imparting specific facts. Williams (2004) argues that facilitators needed to be confident in their role, credible as a professional, and consistent in their tutoring behaviors. Pang et al. (2002) also adumbrates the need for facilitators to share their nursing experiences with students believing that students could relate their problem solving skills with those of their facilitator. Facilitators must also remember that they too need support, and because they are participating in the learning process, should not expect to be considered experts in all areas relating to the problem (Maudsley, 1999). It is therefore important that facilitators are able to resource their own support whether that be through reading material, research or the assistance of academic or clinically based colleagues.

\section{DESCRIPTIONS OF PBL TASKS CURRENTLY USED}

The problem given to the students is usually complex and lengthy. For this reason nursing students explore one problem over a number of weeks. As the weeks pass, the problem is discussed in more depth as the students identify areas where their knowledge base requires improvement. The facilitators in the nursing department find the slow unfolding of the problem over a number of weeks beneficial to the students as this gives the student adequate time to research the problem and rigorously explore surrounding issues. Students often find learning experiences and issues that they wish to investigate that the facilitator may not have considered with this two-way process, adding to the PBL process (Kiley, Mullins, Peterson, \& Rogers, 2000).

\section{How PBL is ASSESSED}

Self assessment is an important part of PBL as students need to be able to identify gaps in their knowledge base in order for more meaningful learning to occur (San Diego State University, 1996). Self directed learning also encourages the student to consider what they do know, what they do not know and what they may need to know in order to accomplish in problems and similar contextual circumstances in the future. On a weekly basis the students in class are required to participate in an oral presentation. Not only does this allow them to share their knowledge and teach each other, it also allows the students to practice their communication skills. These skills are central to nursing student's careers, as much of their working life revolves around presenting ideas and results to their peers and carrying out handovers regarding their patient's care needs and this must profitable educationally as presenting information to real-life audiences is expected to enhance communication skills.

Peer assessment may also be used in the classroom as it promotes cooperation within the PBL environment. Additionally, because life outside the classroom usually requires working with others, peer assessment is also considered a viable option to measure student growth. The facilitator's 
assessment is usually required as they are able to further a student's knowledge base by exploring different ideas, this may include how successful individuals interact within their group and their cognitive growth (Kiley et al., 2000).

Finally, both written and practical exams are used to clarify and strengthen a student's ability to show that they can successfully use the PBL process to apply skills learned during the course to similar problems encountered in practice or subject area domains. In these situations the student works as an individual and can no longer rely on the group to carry their learning load and this completes their theory to practice as they apply their skills (San Diego State University, 1996) which is and must be significant in their overall educational and professional growth.

\section{Commentary on a PBL experience}

Budget constraints will affect the PBL experience both in its construction and how it is delivered and forms part of the conundrum. In some tertiary sites, anecdotal evidence from facilitators suggests they are attempting to teach up to 35 students at a time. The literature is quick to point out that a typical (and ideal) PBL tutorial [should] consist of a group of students (usually eight to ten) and a tutor, who facilitates the session (Carrera, Tellez, \& D'Ottavio, 2003; Wood, 2003). PBL requires small group work and most universities in the United Kingdom have growing student numbers, without similarly growing resources (Piggott, 2003) and this theme tended to be consistent throughout the available research. Having large numbers in the classroom dramatically affects the facilitator's ability to support the student and be aware of what each group is achieving, whereas small numbers facilitate the ideals of the PBL programme and thus presents as a conundrum as many facilitators modify their PBL programmes to accommodate the larger group sizes. This compromise at least gives facilitators the chance of more accurately assessing each student in regard to their PBL progress although compromising the efficacy of PBL in the process, and all of these aforementioned points which examine the ideal and the real in regards PBL form part of the conundrum of this approach.

Other issues of concern are that problems developed may not fully encompass current issues within the clinical setting. This problem may occur due to a range of issues with time constraints on the academic facilitator, or lack of recent clinical practice by people formulating the problems. Also, lack of resources, such as inadequate staff numbers mean that academically rigorous PBL problems/scenarios are not necessarily being developed as the curriculum evolves. As a result of these issues, $\mathrm{PBL}$ at these sites is often a modified PBL approach which tends to fit the rhetoric rather than be a pure PBL approach suggested as the programmes ideal. The degree to which PBL is sometimes modified often leaves staff members somewhat disenchanted, and as a result they may lack rigorous commitment to this style of teaching. Maudsley (1999) explains that due to poor commitment on the facilitator's behalf, misapplication and misconception of PBL can occur within the classroom setting. As a result the student may fail to achieve the anticipated learning outcomes.

\section{Conclusion}

Kirschner et al. (2006) suggest that the practice of a particular profession is not the same as learning to practice the profession and argue that this view falls into line with their claim that the epistemology of a discipline should not be confused with a pedagogy for teaching or learning it. This view would appear to have something to say to nursing courses, with the political decision makers, executives and those that hold the purse strings needing to consider workloads and fiscal considerations as often these imperatives take precedence.

The PBL style which includes minimal guidance is a generally sound educational strategy in and across nursing coursework. The literature indicates that PBL has a range of benefits and students report that the approach provides a much more inviting and friendlier exchange between the academic and student which promulgates the theory-practice gap. This approach encapsulates 
the student being seen as more than an empty vessel needing informational cargo. The paper also addresses some of the difficulties and challenges associated with the PBL approach which include pecuniary interests (or education as a business), group member problems, facilitator issues and the overall design structure of the programme. The challenge and conundrum brought about by PBL is that most facilitators abridge their PBL programmes to incorporate a modified delivery approach which often will include much more guided interaction by facilitators than the PBL approach originally promises. In essence this modified approach takes strength away from the original conception of PBL. If we are to continue using a PBL process in nursing we need to review the parameters, fund the approach properly so that smaller groups can be used to achieve the desired results and also to fund the programme to allow facilitators to add their wisdom to the content of taught programmes. These initiatives would be more in-keeping with positive student results which can be translated across to professional/clinical practice outcomes rather than to delivering a PBL approach to the lowest common denominator driven by fiscal policy directives.

\section{References}

Albanese, M., \& Mitchell, S. (1993). Problem based learning: A review of the literature on its outcomes and implementation issues. Academic Medicine, 69, 52-81.

Azer, S. A. (2001). Problem based learning: Challenges, barriers and outcome issues. Saudi Medical Journal, 22(5), 389-397.

Banning, M. (2005). Approaches to teaching: Current opinions and related research. Nurse Education Today, 25, 502-508.

Barrows, H. S. (1988). The tutorial process. Springfield: Southern Illinois University School of Medicine.

Benner, P. (2000). Shaping the future of nursing. Nursing Management, 7(1), 31-35.

Berkson, L. (1993). Problem based learning: Have the expectations been met? Academic Medicine, 68(10), S79-S88.
Bernstein, P., Tipping, J., Bercovitz, K., \& Skinner, H. A. (1995). Shifting students and faculty to a PBL curriculum: Attitudes changed and lessons learned. Academic Medicine, 70(3), 245-247.

Biley, F. (1999). Creating tension: Under graduate students nurses' response to a problem-based learning curriculum. Nurse Education Today, 19(7), 586-589.

Boud, D., Keogh, R., \& Walker, D. (1995). Reflection: Turning experiences into learning. London: Kogo.

Bridges, E. M., \& Hallinger, P. (1996). Problem based learning in leadership education. New Directions in Teaching and Learning, 68, 53-61.

Capon, N., \& Kuhn, D. (2004). What's so good about problem based learning? Cognition and Instruction, 22(1), 61-79.

Carrera, L. I., Tellez, T. E., \& D’Ottavio, A. E. (2003). Implementing a problem-based learning curriculum in an Argentinean Medical School: Implications for developing countries. Academic Medicine, 78, 798-801.

Colliver, J. (2000). Effectiveness of problem based learning curricula. Academic Medicine, 75, 259-266.

Crosby, J. (1996). AMEE medical education guide No. 8. Learning in small groups. Medical Teacher, 18(3), 99-111.

Das Carlo, M., Swadi, H., \& Mpofu, D. (2003). Medical students' perceptions of factors affecting productivity of problem-based learning tutorial groups: Does culture influence the outcome. Teaching and Learning in Medicine, 15(1), 59-64.

Duke, M., Forbes, H., Hunter, S., \& Prosser, M. (1998). Problem-based learning (PBL): Conceptions and approaches of undergraduate students of nursing. Advances in Health Sciences Education, 3, 59-70.

Edward, K. L., Hercelinskyj, J., Warelow, P., \& Munro, I. (2007). Simulation to practice: Developing nursing skills in mental health: An Australian perspective. International Electronic Journal of Health Education, 10, 60-64.

Finucane, P., Johnson, S., \& Prideaux, D. (1998). Problem-based learning: Its rationale and efficacy. Medical Journal of Australia, 168, 445-448. Haith-Cooper, M. (2002). An exploration of tutors' experiences of facilitating problem based learn- 
ing. Part two: Implications for the facilitator of PBL. Nurse Education Today, 23, 65-75.

Hitchcock, M. A., \& Anderson, A. S. (1997). Dealing with dysfunctional tutorial groups. Teaching and Learning in Medicine, 9(1), 19-24.

Hwang, S. Y., \& Kim, M. J. (2006). A comparison of problem-based learning and lecture-based learning in an adult health nursing course. Nurse Education Today, 26, 315-321.

Johnstone, A., \& Otis, K. (2006). Concept mapping in problem based learning: A cautionary tale. Chemistry, Education, Research and Practice, 7(2), 84-95.

Kenny, N., \& Beagan, B. (2004). The patient as text: A challenge for problem-based learning. Medical Education, 38, 1071-1079.

Kiley, M., Mullins, G., Peterson, R., \& Rogers, T. (2000). Leap into... Problem-based learning. Adelaide: University of Adelaide.

Kirschner, P. A., Sweller, J., \& Clark, R. E. (2006). Why minimal guidance during instruction does not work: An analysis of the failure of constructivist, discovery, problem-based, experiential, and inquiry based teaching. Educational Psychologist, 41, 75-86.

Knowles, M. (1975). Self directed learning: Guide for learners and teaching. Toronto: Prentice Hall.

Levine, A. (2001). Problem based learning, Maricopa Centre for learning and instruction. Retrieved September 29, 2007, from www.mcli. dist.maricopa.edu/pbl/problem.html

Lloyd-Jones, G., Margetson, D., \& Bligh, J. (1998). Problem-based learning: A coat of many colours. Medical Education, 32, 492-494.

Marks, J. (2001). What is problem based learning? Retrieved September 29, from www.imsa.edu/ team/cpbl/whatis/whatis/slide3

Maudsley, G. (1999). Roles and responsibilities of the problem based learning tutor in the undergraduate medical curriculum. British Medical Journal, 318, 657-661.

McCourt, C., \& Thomas, G. (2001). Evaluation of a problem based curriculum in midwifery. Midwifery, 17, 323-331.

McLoughlin, M., \& Darvill, A. (2007). Peeling back the layers of learning: A classroom model for problem-based learning. Nurse Education Today, 27, 271-277.
Mentzelou, P. (2004). The design of a Web-based information technology student support system for higher education, Advanced Learning Technologies, 2004 (pp. 908-909). Proceedings. IEEE International Conference, 30 August-1 September 2004.

Niederhoffer, E. (2000). Southern Illinois University School of Medicine. Retrieved July 23, 2008, from biochem.siuc.edu/som_pbl/PBL.html

Norman, G. (2008). Problem-based learning makes a difference, But why? Canadian Medical Association Journal, 178(1), 61.

Norman, G., \& Schmidt, H. (2000). Effectiveness of problem based learning curricula: Theory, practice and paper darts. Medical Education, 34, 721-728.

Pang, S., Wong, T., Dorcas, K., Allen, L., Lai, C., \& Lee, R. (2002). Evaluating the use of developmental action inquiry in constructing a problem-based learning curriculum for preregistration nursing education in Hong Kong: A student perspective. Journal of Advanced Nursing, 402, 230-241.

Piggott, J. (2003). PBL: A sceptics diary. LTSN website: Retrieved February 2008, from www.economics.ltsn.ac.uk

Pincus, K. V. (1995). Introductory accounting: Changing the first course. New Directions for Teaching and Learning, 61, 88-98.

Rideout, E., England-Oxford, V., Brown, B., Fothergill-Bourbonnais, F., Ingram, C., Benson, G., Ross, M., \& Coates, A. (2002). A comparison of problem based and conventional curricula in nursing education. Advances in Health Sciences Education: Theory and Practice, 7(1), 3-17.

Rowan, C., McCourt, C., \& Beake, S. (2008). Problem based learning in midwifery - The students' perspective. Nurse Education Today, 28, 93-99.

Rowan, C., McCourt, C., Bick, D., \& Beake, S. (2007). Problem based learning in midwifery a teachers' perspective. Nurse Education Today, 27, 131-138.

San Diego State University. (1996). Assessment of problem based learning; students and classes. Retrieved September 29, 2007, from http://edweb. sdsu.edu/clrit.webassess.studentNclasses.html 
Schmidt, H. G. (1983). Problem based learning: Rationale and description. Medical Education, $17,11-16$.

Southern Illinois University School of Medicine. (2000). The minimal essentials for problem based learning in medical education. Retrieved September 29, 2007, from www. Pbli.org/pbl/ medical_pbl.htm

Steinert, Y. (2004). Student perceptions of effective small group teaching. Medical Education, 38(3), 286-293.

Weyers, M. (2006). Teaching the FE curriculum. London: Continuum Publishing Group.
Wilkie, K. (2000). The nature of problem based learning. Basingstoke: McMillan Press.

Williams, A. (1999). An Antipodean evaluation of problem-based learning by clinical educators. Nurse Education Today, 19, 659-667.

Williams, B. (2004). Self direction in a problem based learning program. Nurse Education Today, 24, 277-285.

Wood, D. (2003). ABC of learning and teaching in medicine: Problem based learning. BMJ, 326, $328-330$.

Received 18 September 2008 Accepted 30 July 2009

\section{NOW AVAILABLE}

\section{International Journal of Pedagogies \& Learning}

Research journal of the International Society for Leadership in Pedagogies and Learning (ISLPL)

Editors: Patrick Alan Danaher, Shirley O'Neill and Jeong-Bae Son, Faculty of Education, University of Southern Queensland, Toowoomba QLD, Australia

The International Journal of Pedagogies and Learning (IJPL) is an international, scholarly, independently and anonymously peer-reviewed journal that focuses on issues and trends in pedagogies and learning in local and global contexts and leadership in educational research.

IJPL focuses on research around the essence of pedagogy and learning and related issues and trends. While stimulating discussion of authoritative and emerging pedagogies and forms of learning, it encourages sharing of ideas that contribute to the transformation of contemporary conceptions of pedagogy and learning - in order to reshape and revitalize educational provision for both educators and learners. Research anchored in local, regional and national contexts, with international and transnational in intent and impact, is welcomed.

\section{Volume 5/1 (August 2009)}

Introduction : Special issue on Language Testing - Seyyed Abbas Mousavi

A review of Diplomas de Español como Lengua Extranjera (DELE) - Mignette M Garvida

Redundant versus consistent stems in multiple-choice vocabulary tests and their effects on the pre-university students' performance - Bahman Goriian, Alireza Jalilifar, Halimeh Mousavi

Are teachers teaching to the test? : A case study of the College English Test (CET) in China - Hongli Li

Multimedia as a test method facet in oral proficiency tests Seyyed Abbas Mousavi

EFL proficiency level and differences in Japanese secondary school students' views on the need for pedagogical change Shirley O'Neill
Developing a scoring rubric for a course-specific pair work telephoning speaking assessment using intuitive and databased methods - Fadi Tannouri

Examining washback in second language education contexts : A high stakes provincial exam and the teacher factor in classroom practice in Quebec secondary schools - Carolyn Turner

Protocol analysis in the validation of language tests: Potential of the method, state of the evidence - Ying Zheng

Association of domain-specific knowledge and analytical ability with insight problem solving in mathematics Cumali Oksuz

Evaluation copies available. The journal is included in the membership fee of ISLPL. Information on 2009/10 subscription rates is available from the Publisher or www.ijpl.org

eContent Management Pty Ltd, PO Box 1027, Maleny QLD 4552, Australia Tel.: +61-7-5435-2900; Fax. +61-7-5435-2911; subscriptions@e-contentmanagement.com www.e-contentmanagement.com 
Copyright of Contemporary Nurse: A Journal for the Australian Nursing Profession is the property of eContent Management Pty. Ltd. and its content may not be copied or emailed to multiple sites or posted to a listserv without the copyright holder's express written permission. However, users may print, download, or email articles for individual use. 